\title{
Fertility of the two crucians species of the lake Big Taraskul Taskaeva K. ${ }^{1}$, Bakina A. ${ }^{2}$, Yankova N. ${ }^{3}$ \\ Плодовитость двух видов карасей озера Большой Тараскуль Таскаева К. Р. ${ }^{1}$, Бакина А. В. ${ }^{2}$, Янкова Н. В. ${ }^{3}$
}

\author{
${ }^{I}$ Таскаева Кира Расимовна / Taskaеva Kira-аспирант; \\ ${ }^{2}$ Бакина Алёна Васильевна / Bakina Alena - старший лаборант-исследователь, \\ аспирант: \\ ${ }^{3}$ Янкова Наталья Васильевна / Yankova Natalya - кандидат биологических наук, старший научный сотрудник, \\ Госрыбцентр, \\ доиент, \\ кафедра водных биоресурсов и аквакультуры, \\ Институт биотехнологии и ветеринарной медицинь \\ Государственный аграрный университет Северного Зауралья, г. Тюмень
}

\begin{abstract}
Аннотация: в статье приведен половой состав серебряного и золотого карасей. Получены новые данные по плодовитости карасей. Представлена зависимость между длиной, массой и индивидуальной абсолютной плодовитостью на рисунках.

Abstract: the paper presents the sex composition of the silver and gold crucians. New data on fertility of crucians. The dependence of the length, weight and the individual absolute fertility presents in the figures.
\end{abstract}

Ключевые слова: серебряный карась, золотой карась, индивидуальная абсолютная плодовитость, индивидуальная относительная плодовитость, гонадосоматический индекс.

Keywords: silver crucian, golden crucian, the individual absolute fertility, individual relative fertility, gonadosomatic index.

Озеро Большой Тараскуль можно отнести к гумозно-эвтрофному водоему заморного типа. Мелководное карасевое озеро, в котором обитают серебряный и золотой караси, а также вселившийся ротан-головёшка, при этом численность золотого карася в последние годы существенно снизилась [8].

Снижение численности золотого карася - это общая тенденция во многих водоемах, существует немало работ, посвященных такому явлению [2, 10]. Изучение плодовитости рыб является важным условием для получения полной картины о состоянии уровня естественного воспроизводства популяций в текущий период.

Материал для данной работы собран в преднерестовый период, в мае 2016 г. на типичном заморном водоеме Большой Тараскуль Тюменского района. Всего исследовано 34 экземпляра серебряного карася Carassius auratus (L., 1758) и 57 экземпляров золотого карася Carassius carassius (L., 1758). Отлов рыбы проводили при помощи ставных комбинированных сетей с ячеей 16, 22, 30, 36, 40, 45, 50, 60 мм. Обработку материала проводили согласно общепринятым в ихтиологии методикам [5]. Возраст карасей определяли по чешуе. При определении плодовитости пользовались счетно-весовым методом [6].

Особенность популяций серебряного карася проявляется в том, что обычно самки по численности значительно преобладают самки, например, во многих озерах Урала и более северной части Тюменской области численность самок составляла 96-98\% [3]. В оз. Большой Тараскуль все исследованные особи серебряного карася были половозрелыми. Соотношение самцов и самок составило почти 1:2 (Рисунок 1). Для озер Ханты-Мансийского округа также отмечалась характерная биологическая особенность, так в $о 3$. Узкое соотношение полов составило 6:1 в пользу самок [7].

В выборке золотого карася оз. Большой Тараскуль также все рыбы были половозрелыми, количество самцов и самок при этом составило почти 5:1.

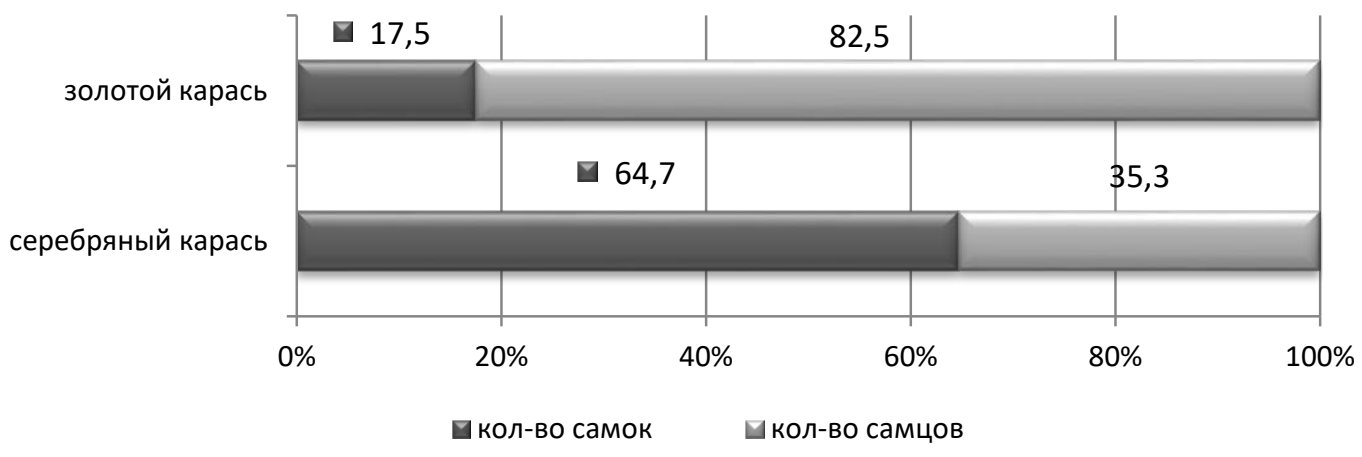


Рис. 1. Половая структура популяциий карасей оз. Большой Тараскуль, май 2016 г.

В свое время, А. Н. Петкевич и Г. И. Никонов [3] отмечали: у золотого карася повсеместно соотношение самцов и самок составляло 1:1, реже наблюдали незначительное преобладание самцов. Также в озёрах Ханты-Мансийского округа оно было близко 1:1, и лишь в отдельных озерах соотношение могло смещаться в ту или иную сторону [7].

Таким образом, в нерестовый период 2016 г. в оз. Большой Тараскуль в уловах золотого карася доминировали самцы, следовательно, потенциал воспроизводства золотого карася в текущий период значительно снижен по сравнению с 60-70-ми годами XX века за счет сокращения доли самок.

В таблице 1 представлены результаты расчетов плодовитости серебряного карася. Анализируя данные по абсолютной плодовитости серебряного карася, было установлено, что среднее значение данного показателя в исследованной выборке рыб возрастного диапазона 5+-8+ достигает 47285 икринок, при колебании от 18435 до 84511 штук. У старшевозрастных особей более высокий показатель индивидуальной абсолютной плодовитости.

Таблииа 1. Показатели плодовитости серебряного карася озера Большой Тараскуль

\begin{tabular}{|c|c|c|c|c|c|c|}
\hline Возраст & $\begin{array}{c}\text { Промысловая } \\
\text { длина, см }\end{array}$ & Масса, г & ГСИ, \% & ИАП, шт. & ИОП, шт. & п, экз. \\
\hline $5+$ & $15,1 \pm 0,81$ & $112,7 \pm 23,32$ & $17,91 \pm 4,79$ & $33138 \pm 13150$ & $398 \pm 106$ & 3 \\
\hline $6+$ & $17,5 \pm 0,24$ & $174,2 \pm 10,90$ & $15,38 \pm 0,59$ & $43757 \pm 3801$ & $348 \pm 26$ & 13 \\
\hline $7+$ & $18,8 \pm 0,44$ & $275,1 \pm 56,34$ & $17,06 \pm 0,50$ & $61779 \pm 6446$ & $399 \pm 52$ & 5 \\
\hline $8+$ & 22,6 & 362,0 & 14,66 & 63126 & 224 & 1 \\
\hline Всего & $17,7 \pm 0,38$ & $197,3 \pm 19,23$ & $16,07 \pm 0,69$ & $47285 \pm 3659$ & $361 \pm 24$ & 22 \\
\hline
\end{tabular}

По сравнению с данными других исследований озер юга Тюменской области, показатели индивидуальной плодовитости серебряного карася были выше, так средняя максимальная абсолютная плодовитость в оз. Кучаково [9] - характеризуется наиболее благоприятными экологическими условиями среди исследованных озер, достигала 26,43 тыс. икринок. Абсолютная плодовитость карася серебряного в водоемах Ханты-Мансийского округа колебалась от 12 до 238,7 тыс. икринок. Средняя максимальная плодовитость исследованных озер (оз. Малое Шумиловское) составила 70,3 тыс. икринок [7]. Абсолютная плодовитость карася серебряного из оз. Шумиловское изменялась от 5,6 до 168,0 тыс. икринок, составляя в среднем 67,9 тыс. икринок [4]. Построены уравнения регрессии показателей ИАП от длины и массы рыб. Они свидетельствуют, что у одноразмерных особей серебряного карася продуцируется значительно больше икры, чем у золотого (Рисунки 2, 3).

Индивидуальная относительная плодовитость серебряного карася оз. Большой Тараскуль варьировала от 212 до 582 икринок, в среднем составила: 361 икринка на 1 г веса. В сравнении с показателями относительной плодовитости из других озер юга Тюменской области [9] полученные результаты выше. Например, индивидуальная относительная плодовитость оз. Мостовое максимально достигала 356 икринок, а в среднем составляла 173 икринки.

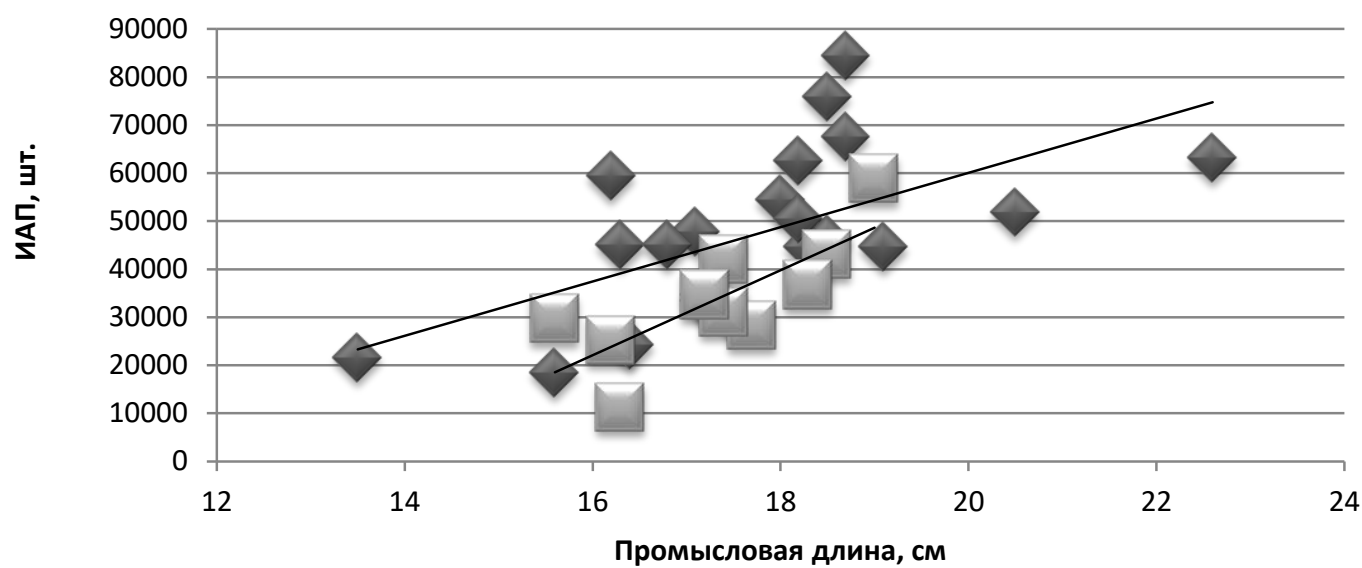

\footnotetext{
$\diamond$ серебряный карась

— Линейная (серебряный карась)

$y=5653,2 x-53034$

$R^{2}=0,3503$
}

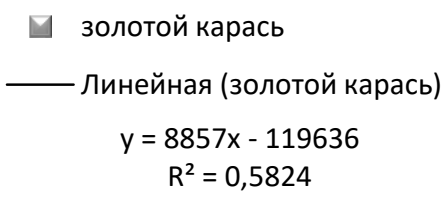


Рис. 2. Зависимость индивидуальной абсолютной плодовитости карасей оз. Большой Тараскуль от промысловой длины тела

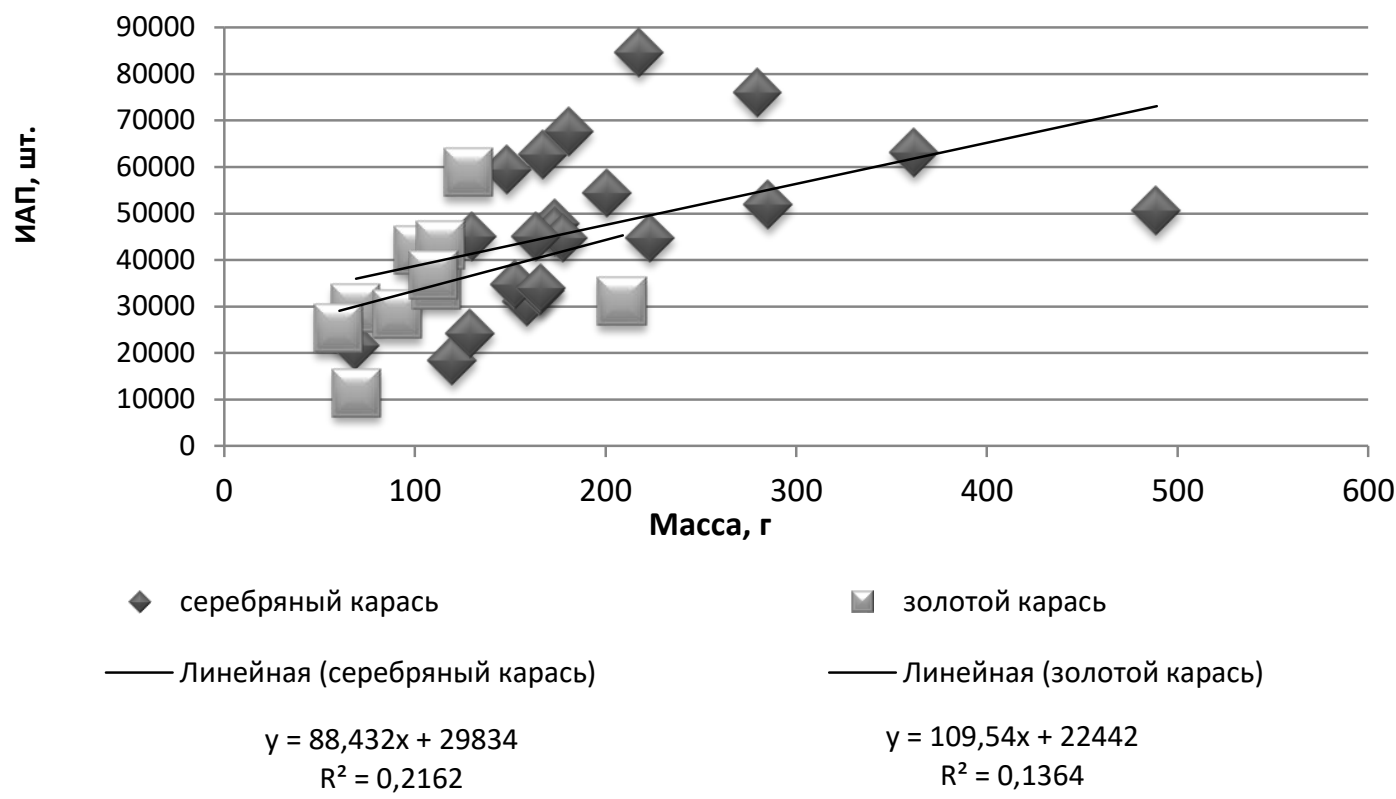

Рис. 3. Зависимость индивидуальной абсолютной плодовитости карасей оз. Большой Тараскуль от массы тела

Отношение веса половых продуктов к весу тела у созревших самок (ГСИ) серебряного карася оз. Б. Тараскуль составляет 12,61-27,47\%, в среднем 16,07\%. Коэффициент зрелости карася серебряного озер Ханты-Мансийского округа немногим уступает, где наименьший $9,5 \%$, наибольший $-22,2 \%$, в среднем $14,2 \%$ [7]. У А. А. Полукеева [4] отмечен широкий диапазон колебания гонадосоматического индекса $3,93-39,66 \%$.

В таблице 2 представлены результаты расчетов плодовитости золотого карася. По нашим данным средняя индивидуальная абсолютная плодовитость золотого карася составляла 34121 икринок, минимальная зафиксирована в количестве 11365 штук у особи длиной 12,6 и массой 69,8 г, максимальная у самки длиной 15,5 см и массой 128,4 г составила 58864 штуки.

Таблица 2. Показатели плодовитости золотого карася озера Большой Тараскуль

\begin{tabular}{|c|c|c|c|c|c|c|}
\hline Возраст & $\begin{array}{c}\text { Промысловая } \\
\text { длина, см }\end{array}$ & Масса, г & ГСИ, \% & ИАП, шт. & ИОП, шт. & $\begin{array}{c}\text { п, } \\
\text { экз. }\end{array}$ \\
\hline $4+$ & $12,5 \pm 0,1$ & $66,4 \pm 3,0$ & $16,04 \pm 2,15$ & $22096 \pm 5524$ & $462 \pm 127$ & 3 \\
\hline $5+$ & 14,2 & 91,2 & 19,20 & 28308 & 416 & 1 \\
\hline $6+$ & $14,3 \pm 0,33$ & $134,3 \pm 25,0$ & $21,17 \pm 4,66$ & $37744 \pm 2930$ & $444 \pm 95$ & 4 \\
\hline $7+$ & $15,2 \pm 0,25$ & $119,1 \pm 9,3$ & $25,56 \pm 1,84$ & $47821 \pm 11043$ & $561 \pm 96$ & 2 \\
\hline Всего & $13,9 \pm 0,36$ & $106,6 \pm 13,4$ & $20,31 \pm 2,38$ & $34121 \pm 3979$ & $470 \pm 52$ & 10 \\
\hline
\end{tabular}

Абсолютная плодовитость рыб находится в прямой зависимости от возраста и веса производителей. Более старшие, крупные рыбы продуцируют большее количество икры, такое свойство отмечали многие ученые $[1,3,4,7,9]$.

Индивидуальная относительная плодовитость золотого карася оз. Большой Тараскуль варьировала от 210 до 657 икринок, в среднем составляя 470 икринок.

Гонадосоматический индекс золотого карася оз. Б. Тараскуль в период исследований варьировал от $8,22 \%$ до 27,41\%, в среднем составляя 20,31\%. Коэффициент зрелости золотого карася озер ХантыМансийского округа также ниже, как и у карася серебряного, где колебания составили 6,6-21,0\%, в среднем - 14,4\% [7].

Таким образом, караси озера Большой Тараскуль имеют более высокие показатели относительной плодовитости, чем показатели карасей из других водоемов.

Серебряный карась озера Большой Тараскуль имеет более высокие показатели плодовитости, чем золотой, что, вероятно, наряду с существенно более низкой долей самок в его популяции приводит к сокращению численности золотого карася.

В целом, полученные нами результаты по плодовитости популяций двух видов карасей в оз. Большой Тараскуль свидетельствуют о достаточно высоком по сравнению с другими озерами региона потенциале 
воспроизводства у серебряного карася и низком уровне воспроизводительной способности в популяции золотого, из-за преобладания самцов и более низких показателей абсолютной плодовитости самок, что, вероятно, частично компенсируется более высокой относительной плодовитостью этого вида.

\section{Лumepamypa}

1. Иоганзен Б. Г., Петкевич А.Н. Плодовитость промысловых рыб Западной Сибири. Изд-е Барабинского отделения ВНИОРХ, 1958. Новосибирск. С. 36-37.

2. Межжерин С. В., Кокодий С. В., Кулиш А. В., Верлатый Д. Б., Федоренко Л. В. Гибридизация золотого карася (Carassius carassius (Linnaeus, 1758)) в водоемах Украины и генетическая структура гибридов // Цитология и генетика, 2012. 46. № 1. С. 37-46.

3. Петкевич А. Н., Никонов Г. И. Караси Сибири. Состояние запасов и рациональное их использование. Свердловск, Средне-Уральское кн. изд-во, 1974. 56 с.

4. Полукеев A. A. Биология карася серебряного в водоемах Ханты-Мансийского округа // Тр. ОбьТазовского отделения / Под ред. А. Н. Петкевича. Новая серия. Том 4. Свердловск: Средне-Уральское кн. изд-во, 1977. С. 69-75.

5. Правдин И. Ф. Руководство по изучению рыб. Москва, 1966. 376 с.

6. Спановская В. Д., Григораш В. А. К методике определения плодовитости единовременно и порционно икромечущих рыб // Типовые методики исследования продуктивности рыб в пределах их ареалов. Вильнюс, 1976. Ч. 2. С. 54-62.

7. Судаков В. М. Рыбное хозяйство Обь-Иртышского бассейна. // Тр. Обь-Тазовского отделения / Под ред. А. Н. Петкевича. Новая серия. Том 4. Свердловск: Средне-Уральское кн. изд-во, 1977. С. 46-53.

8. Таскаева К. Р., Коваленко А. И., Янкова Н. В. Современное состояние экосистемы озера заморного типа Большой Тараскуль // Материалы Междунар. науч.-практ. конф. для аспирантов и молодых ученых «Новый взгляд на решение проблем АПК», посвящ. 70-летию Победы в Великой Отечественной войне / Молодой учёный, 2015. № 6.5 (86.5). С.174-176.

9. Янкова Н. В. Изменчивость плодовитости серебряного карася в разнотипных озерах юга Тюменской области // Новый взгляд на проблемы АПК: сборник к конференции молодых ученых, декабрь 2002 г. ТГСХА, Тюмень, 2002. С. 64-66.

10. Янкова Н. В., Ниязов Н. С., Мухачев И. С. Рациональное использование запасов карасей водоемов Тюменской области // Рыбное хозяйство, 2006. Вып. 5. С. 53-55. 